\title{
A new device for the application of electrical shock
}

MAURICE E. T. SWINNEN, JOSEPH V. BRADY, and MARSHALL G. POWELL, WALTER REED ARMY INSTITUTE OF RESEARCH, Washington, D.C. 26012 and THE JOHNS HOPKINS UNIVERSITY, Baltimore, Maryland 21218

A new apparatus has been developed for the simple, safe, and effective delivery of electric shock. It delivers a single-pulse high-voltage shock of very short duration. Both voltage and current are easily measured and the applied energy can be calculated. Constant energy applications depend less upon skin contact resistance than is the case with $600-\mathrm{V} 60-\mathrm{Hz}$ shockers.

The electrical shocker described in this report overcomes most of the shortcomings of conventional $60-\mathrm{Hz}$ shockers (Campbell \& Teghtsoonian, 1958; Forbes \& Bernstein, 1935; Kellog, 1941; Muenzinger \& Walz, 1932, 1934). The peak voltage is high enough to minimize high skin-contact resistance. Monkeys in restraining chairs can be shocked through loose-fitting collars without shaving or application of conductive paste. ${ }^{1}$

This unit delivers one, and only one, pulse of very short duration, each time ground is applied to the operate stud. Accidental sticking of the relay has no other effect than to render the apparatus inoperative with the output remaining at zero volts. Accidental contact with the output by the operator, although not recommended, does not cause prolonged muscular contraction, as is the case with $60-\mathrm{Hz}$ shockers. The single shock is of very short duration and it is impossible to apply continuous shock, as could be done in the case of a cattle prod, to which this device is somewhat related.

Figure 1 shows a schematic circuit diagram of the shocker.

A capacitor is charged to $28 \mathrm{~V} \mathrm{dc}$ through a $27-0$ hm resistor and the normally closed contacts of the relay. This readies the shocker. The time required for the capacitor to reach near asymptotic charge level is roughly five times the time constant Cx 27 ohms. With $C$ equal to $50 \mathrm{mF}$, this time equals approximately $7 \mathrm{msec}$. When a ground pulse is applied to the operate input, the relay is activated and the capacitor is discharged into the primary of an automobile spark coil. This coil is a transformer with a turns ratio of about 1:200. The output pulse amplitude is therefore about $2 \mathrm{~V} \times 200=5600 \mathrm{~V}$ peak. The pulse duration is about $4 \mathrm{msec}$. To avoid multiple output pulses due to relay bounce, a relay with mercury-wetted contacts should be used.

The energy applied with each shock is constant, provided both the capacitor and the charging voltage are constant. The energy stored in the capacitor is calculated by $E=\left(C^{2}\right) / 2$, where $E$ is the stored energy in joules or wattseconds, $C$ the value of the capacitor in farads and $\mathrm{V}$ the charging voltage in volts. By connecting several capacitors to a multipole switch, one can choose the correct value of energy required to produce the desired shock level.

Reasonable care should be taken in connecting the high-voltage output to the grids, collar, or other electrode. Only high-voltage

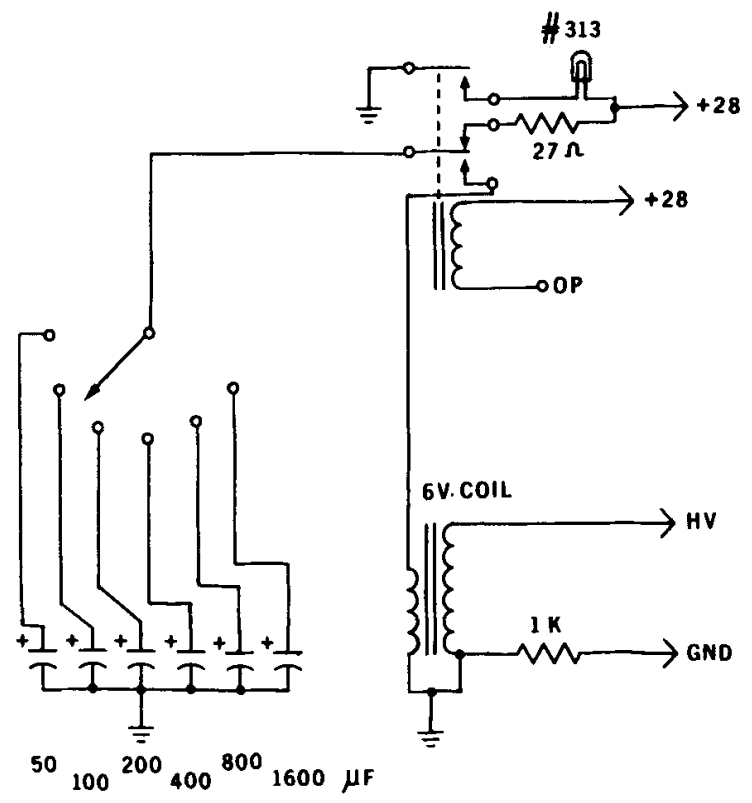

Fig. 1. Circuit diagram of shocking device.

spark-plug leads, obtainable at auto-parts dealers, should be used for this purpose. The high-voltage return lead, which is internally connected to the spark coil casing, should be grounded. The voltage developed across a 1000 -ohm resistor in the ground return lead can be displayed on an oscilloscope and will give a scale factor of $1 \mathrm{~V} / \mathrm{mA}$ instantaneous current applied.

In case of grid bars, every alternate grid bar should connect to the high-voltage output and the bars in between should be returned to ground through the 1000 -ohm resistor. Grid shock scramblers cannot be used with this shocker, as the distance between individual relay contacts is too small to prevent arcing of the high-voltage pulse resulting in greatly reduced output voltage.

\section{REFERENCES}

CAMPBELL, B. A., \& TEGHTSOONIAN. R. Electrical and behavioral effects of different types of shock stimuli on the rat. Journal of Comparative Psychology, 1958, 2, 185-192.

FORBES, T. W., \& BERNSTEIN, A. L. The standardization of $60 \mathrm{cycle}$ electrical shock for practical use in psychological experimentation. Joumal of General Psy chology, 1935, 12, 436.

KELLOG, W. N. Electrical shock as motivating stimulus in conditioning experiments. Journal of General Psychology, 1941, 25, 85.

MUENZINGER, K. F., \& WALZ, F. C. An analysis of the electrical stimulus producing shock. Joumal of Comparative Psychology, 1932, 13, 157-171.

MUENZINGER, K. F., \& WALZ, F. C. An examination of electric cursent stabilizing devices for psychological experiments. Joumal of General Psychology, 1934, 10,477.

\section{NOTE}

1. The principles of laboratory animal care as promulgated by the National Society for Medical Research were observed. 